\title{
An Experimental Study of Reinforced Concrete Beams with Closely-Spaced Headed Bars
}

\author{
Kah Mun Lam, ${ }^{1)}$ Woosuk Kim, ${ }^{2)}$ Michael Van Zandt, ${ }^{1)}$ and Thomas H.-K. Kang ${ }^{3), *}$
}

(Received January 31 2011, Revised October 4, 2011, Accepted October 7, 2011)

\begin{abstract}
The use of headed bars as opposed to standard 90- or 180-degree hooked bars in beam ends, beam-column joints or other steel congested areas for anchorage and bond has become more favorable due to the fact that steel congestion is often created by large bend diameters or crossties. This research mainly focuses on evaluating the code provisions regarding the use of headed bars. Nine simply supported rectangular concrete beams with headed longitudinal reinforcement were tested under a four-point monotonic loading system. The design clear spacing, which varies from 1.5 to 4.25 times the bar diameter, was the only parameter for the experimental investigation. The test results showed that the closely-spaced headed bars were capable of developing to full yield strength without any severe brittle concrete breakout cone or pullout failure. Bond along the bar was not sufficient due to the early loss of concrete integrity. However, the headed bars were effective for anchorage with no excessive moment capacity reduction. This implies that the clear spacing of about 2 times the bar diameter for headed bars may be reasonable to ensure the development of specified yield strength of headed bars and corresponding member design strength.
\end{abstract}

Keywords: headed bar, bond, development, anchorage, experiment.

\section{Introduction}

Steel congestion in structural concrete poses a problem in concrete design when large bend diameters and long development length of conventional reinforcing bars are being used in order to satisfy the code provisions given in ACI 318-08 (Section 12.6). ${ }^{2}$ Especially in beam ends and beam-column joints such as are found in structural buildings and bridges, 90- or 180-degree hooked reinforcing bars are commonly used and cause a lot of complications in fabrication and concrete workability. Requirements can sometimes scarcely be met with large bend diameters and long development length in any dimension of the elements.

To provide a solution for these issues, headed bars are used in construction when the strength development of the reinforcing bars needs to be achieved within a shorter distance and without large bend diameters. In general, a headed bar has the same specifications as a straight or hooked reinforcing bar but with a head attached at the end of the bar. The head acts like a steel bearing plate; thus, not only bond forces are transferred along the bar but also very large bearing pressure is also created at the face of the

\footnotetext{
${ }^{1)}$ School of Civil Engineering and Environmental Science, University of Oklahoma, Norman, OK 73019, USA.

${ }^{2}$ KCI Member, School of Architecture and Civil Engineering, Kyungpook National University, Daegu 702-701, Korea.

${ }^{3}$ KCI Member, Dept. of Architecture and Architectural Engineering, Seoul National University, Seoul 151-744, Korea. *Corresponding Author, E-mail: tkang@snu.ac.kr

Copyright (c) 2011, Korea Concrete Institute. All rights reserved, including the making of copies without the written permission of the copyright proprietors.
}

head. If this pressure exceeds concrete bearing stress capacity, a cone-shaped chunk of concrete is removed when the bars are pulled.

The stress created by the upset bearing against the head may raise a concern regarding the clear spacing between the reinforcing bars. The concrete failure surface is typically shared among the headed bars to sustain the total bar force (Fig. 1). Clear spacing of the bar is an important aspect as the size and dimension of the beam may be determined based on the clear spacing, which may result in very inefficient design when a large diameter headed bar is used. Previous experimental research with exterior beam-column joints with headed bars and headed bar pullout test specimens ${ }^{5,7,8}$ has been done to investigate other issues regarding the effectiveness of different head and bar size, head shape and head-attaching techniques and to evaluate their performance in comparison with standard hooks. However, there is little research regarding the clear spacing between headed bars anchored in the beam ends. In this study, the effect of the design parameter of clear bar spacing on the behavior of reinforced concrete flexural beams is experimentally examined. The test results would be helpful to update the conservative requirements in ACI 318-08, particularly for the clear spacing between headed bars and bars under stacked conditions, provided that more data are generated in the future.

\section{Development and anchorage of conventional and headed reinforcement}

This section discusses the design provisions for conventional and headed reinforcing details presented in ACI 318-08. The anchorage details are also discussed to emphasize the behavior of headed anchors in concrete used to transmit structural loads. The 


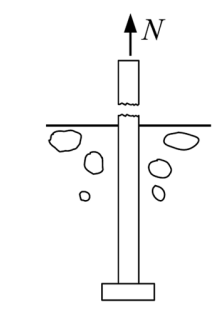

Steel fracture

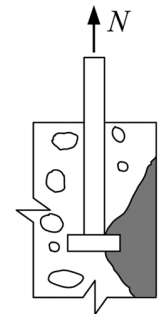

Side-face blowout

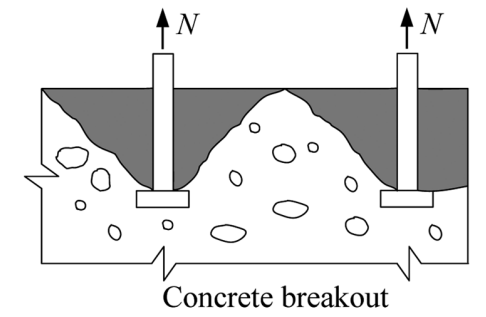

Fig. 1 Failure modes for headed anchors or straight bars. (ACI 318-08)

typical mode of failures for headed anchors is reviewed in connection with ACI 318-08, Appendix D.

\subsection{ACI 318 development length provisions}

ACI 318-08 "Building Code Requirements for Structural Concrete" Section 12.2, "The Development and Splices for Reinforcement," specifies the basic equations to determine the required development length of a straight deformed bar(s) in tension by using two basic methods for calculation: either selecting the simplified equation from a table in Section 12.2.2 or calculating using the more conservative equation in Section 12.2.3. Development length is especially important when a large number of highly stressed bars are embedded that tend to create a weakened plane and cause longitudinal cracks to propagate along the bar.

The use of standard hooks is another option to provide the required development length when no sufficient embedment length is available, especially on beam ends and beam-column joints. The bends and hooks can sometimes be large in size and the specific reinforcing details like the bend radius can also cause complications during concrete casting. ACI 318-08 specifies the 90- and 180-degree standard hook detailing in Section 12.5, and the development length equation in Section 12.5.2 for standard hooks. Research conducted by Mains ${ }^{9}$ shows through a series of pullout tests and beam specimen tests that the hooked bar performed as well as the hooked deformed bar. Other research related to standard hooks ${ }^{10}$ also performed tests on the bent anchorage capacity by comparing the straight and hooked 90- and 180-degree bars. The results show that the larger the bend angle, or the shorter the ratio of bend radius to bar diameter, the more likely the bar tends to slip at a given bar stress. Hence, the deformed bar with a 90- degree standard hook is preferable to sustain firmness of the anchorages.

The code provisions did not specify details for the development length with headed deformed bars until the current revised version of ACI 318-08. ACI 318-08, Section 12.6.2 specifies the equation for calculating the development for headed deformed bars, while Section 12.6.1 specifies the details of headed deformed bars. The requirements shown in Section 12.6.1 are rather conservative, and if followed strictly, the fabrication of beams and beam-column joints may be unrealistic in dimension. Section 3.5.9 also states that the obstruction of deformation has to be within $2 d_{b}$ from the bearing surface of the head which is also in conformity with ASTM A970, ${ }^{3}$ where $d_{b}$ is the bar diameter. This limitation is mostly due to the variety of methods used to attach the head or steel plate at the end of the bar and the lack of test data for headed bars with obstruction of deformation outside $2 d_{b}$. The net bearing area of the head is equal to the gross area of the head minus the area of the obstruction. The headed deformed bar relies on the bearing on the head as well as the bond stresses along the deformed bar., ${ }^{4,8}$

The development length equation for headed deformed bars is as follows:

$$
l_{d t}=\frac{0.19 \psi_{e} f_{y} d_{b}}{\sqrt{f_{c}^{\prime}}} \geq \text { the larger of } 8 d_{b} \text { and } 152 \mathrm{~mm}
$$

where $f_{y}$ is the specified strength of headed bars, $f_{c}^{\prime}$ is the specified concrete strength, $d_{b}$ is the bar diameter, and $\psi_{e}=1.2$ for epoxy-coated reinforcement and 1.0 for other cases. A reduction factor of $\left(A_{s, \text { required }} / A_{s \text {,provided }}\right)$ may be applied to Eq. (1), where $A_{s}$ is the total bar area in tension. One of the disadvantages is that Eq. (1) does not account for the head size of the bearing. According to the research by DeVries et al. ${ }^{5}$, the head geometry has an effect on the ultimate anchorage capacity, and the geometry of the head should be designed such that the head has enough stiffness to reduce the effective bearing capacity and allow yielding after pullout cone failure occurs. DeVries et al. ${ }^{5}$ also reported that transverse reinforcement that is placed perpendicular to the bar does not really affect the anchorage capacity.

\subsection{Failure modes for headed anchors}

ACI 318-08, Appendix D describes the typical failure modes for steel elements with anchors under tensile and shear loading. Appendix D.5 specifies the design requirements for anchors under tensile loading. This subsection only discusses the design provisions under tensile loading conditions. Figure 1 shows the typical failure modes of steel anchors in tension. The steel strength of anchors in tension is specified in Appendix D.5.1. The nominal strength $\left(N_{s a}\right)$ of a headed anchor or group of anchors in tension depends on the material properties and physical dimensions of the anchor. The concrete breakout strength $\left(N_{c b}\right)$ and pullout strength $\left(N_{p n}\right)$ of a headed anchor in tension are specified in Appendix D.5.2 and D.5.3, respectively. The concrete side-face blowout strength $\left(N_{s b}\right)$ is specified in Appendix D.5.4. The readers are referred to ACI 318-08, Appendix D.5 for detailed equations.

\section{Experimental program}

ACI 318-08, Section 12.6 requires that the clear spacing 
between the headed bars should be at least $4 d_{b}$. This conservative limitation was adopted as a result of lack of research on headed bars. One of the main purposes of this provision is to prevent the headed bars from sharing the same concrete breakout failure surface, as large bearing pressure may be created upon the surface of the head when the reinforcement is in tension. However, the provision of Section 12.6 would increase the size of the beam impractically. In this experiment, reinforced concrete beams with headed bars were designed based on requirements in ACI 318-08 Section 12.6, except for the clear bar spacing requirement. All the reinforcing details, concrete properties, modification factors and development length equations were chosen in accordance with Section 12.6. The specimens were designed to be tested under a four-point monotonic loading system. The following subsections discuss the test specimen design, instrumentation, testing setup and procedure.

\subsection{Specimen design}

In order to investigate the effect of smaller clear spacing on headed bars in concrete beams, nine reinforced concrete beam specimens with headed bars were designed and fabricated (Table 1). The four-point loading test can demonstrate the condition of a cantilever beam under a point load on the tip of the beam. In this case, the critical section located at the interface of the column and the beam can be represented by the critical section on the loading point of the beam specimens. Since the test was a four-point loading system, two sides of each beam were investigated simultaneously.

The specimens were designed with a length of 2,440 $\mathrm{mm}$ and a dimensional section of $200 \mathrm{~mm}$ by $355 \mathrm{~mm}$. A spreader beam was used to induce a four-point loading system on top of the specimens. The maximum allowable length for the spreader beam was $1,220 \mathrm{~mm}$. Therefore, the two loading points on the specimens were designed to be located at a $610 \mathrm{~mm}$ offset from the beam centerline in both directions. The shear span from the support to the loading point was $21 \mathrm{in}$. ( $a / d=1.7$, except for BH1-A with $a / d$ $=2.7$ and $\mathrm{BH} 2$ with $a / d=2.1$ ). Design concrete compressive strength was $28 \mathrm{MPa}$. For primary tension reinforcement, D13, D16 and D19 headed bars with design yield strength of $420 \mathrm{MPa}$ were used. Larger diameter headed bars can be tested in future study. The combination of headed bar sizes chosen as reinforcement on each beam was solely based on the clear spacing allowed between the cut-off bar beyond the critical section.

Since the primary objective of this experimental program is to study the effect of reduced clear spacing between headed bars, the

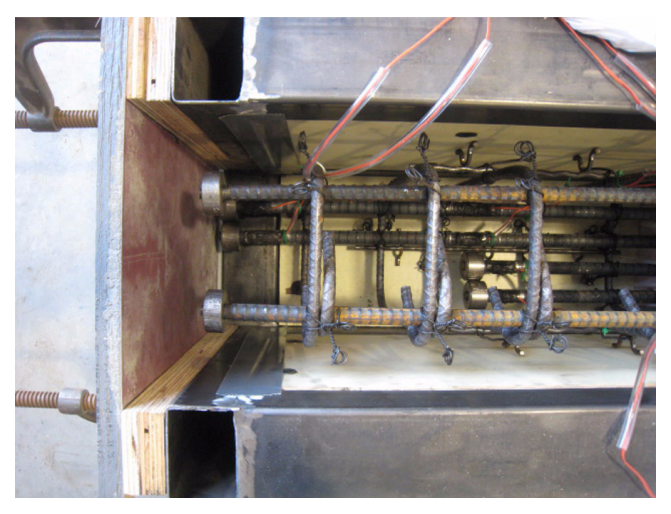

Fig. 2 Beam end reinforcing details for $\mathrm{BH} 1-1 \mathrm{~A}$.

tension reinforcement was not provided throughout the entire length of the beam. Part of the tension reinforcement was cut-off at $l_{d t}$ distance from the loading point. The moment capacity at the cut-off point was more than that of the calculated applied moment for all of the nine specimens to ensure no flexural failure at that point. Figure 2 shows the cut-off bar section of a fabricated reinforcing cage for specimen BH1-1A that was placed inside the formwork. To enable testing of the side spalling effect or side-face blowout failure, the cut bar was not placed in between the two long bars. The design clear bar spacing between the headed bars region were $1.5 d_{b}, 2 d_{b}, 2.25 d_{b}, 2.75 d_{b}$ and $4.25 d_{b}$, respectively. Two beams (A and B) with identical reinforcing details and clear spacing were designed. As for the specimen with $2.75 d_{b}$, only one beam was so designed due to the complication of fabrication. Figure 3 shows the reinforcement layout, dimensions and strain gauge and LVDT locations for all specimens. The following summarizes the features of the nine beam specimens.

i. Specimens BH1-1A and BH1-1B: Reinforced concrete beams containing four D16 headed bars and clear spacing of $1.5 d_{b}$ between bars at cut-off region, with two D16 bar cut off at $l_{d t}$ of $240 \mathrm{~mm}$ from the loading point.

ii. Specimens BH1-2A and BH1-2B: Reinforced concrete beams containing two D13 and two D16 headed bars and clear spacing of $2 d_{b}$ between bars at cut-off region, with one D13 and one D16 bar cut off at $l_{d t}$ of $240 \mathrm{~mm}$ from the loading point.

iii. Specimens BH1-3A and BH1-3B: Reinforced concrete beams containing two D13 and two D19 headed bars and clear spacing of $2.25 d_{b}$ between bars at cut-off region, with one D13 and one D19 bar cut off at $l_{d t}$ of $290 \mathrm{~mm}$ from the loading point.

Table 1 Test specimens reinforcing details.

\begin{tabular}{c|c|c|c|c}
\hline Specimen & Layer & Longitudinal bar diameter, $d_{b}(\mathrm{~mm})$ & Clear bar spacing, $c_{s}$ & Clear cover, $c_{c}$ \\
\hline \hline BH1-1A & Single & D16 $(16 \mathrm{~mm})$ & $1.5 d_{b}$ & $2.2 d_{b}$ \\
\hline BH1-1B & Single & D16 $(16 \mathrm{~mm})$ & $2.5 d_{b}$ & $2.2 d_{b}$ \\
\hline BH1-2A & Single & D13 $(13 \mathrm{~mm}) \& \mathrm{D} 16(16 \mathrm{~mm})$ & $2 d_{b}$ & $2.2 d_{b}$ \\
\hline BH1-2B & Single & $\mathrm{D} 13(13 \mathrm{~mm}) \& \mathrm{D} 16(16 \mathrm{~mm})$ & $2.25 d_{b}$ & $2.2 d_{b}$ \\
\hline BH1-3A & Single & $\mathrm{D} 13(13 \mathrm{~mm}) \& \mathrm{D} 19(19 \mathrm{~mm})$ & $2.25 d_{b}$ & $2.2 d_{b}$ \\
\hline BH1-3B & Single & $\mathrm{D} 13(13 \mathrm{~mm}) \& \mathrm{D} 19(19 \mathrm{~mm})$ & $4.25 d_{b}$ & $2.2 d_{b}$ \\
\hline BH1-4A & Single & $\mathrm{D} 13(13 \mathrm{~mm})$ & $2.25 d_{b}$ & $2.2 d_{b}$ \\
\hline BH1-4B & Single & $\mathrm{D} 13(13 \mathrm{~mm})$ & $2.75 d_{b}$ & $2.2 d_{b}$ \\
\hline BH2 & Double & D16 $(16 \mathrm{~mm}) \& \mathrm{D} 19(19 \mathrm{~mm})$ & &
\end{tabular}

$\mathrm{BH}=$ Beam with headed bars.

Note: Two identical specimens (A, B) were tested. 

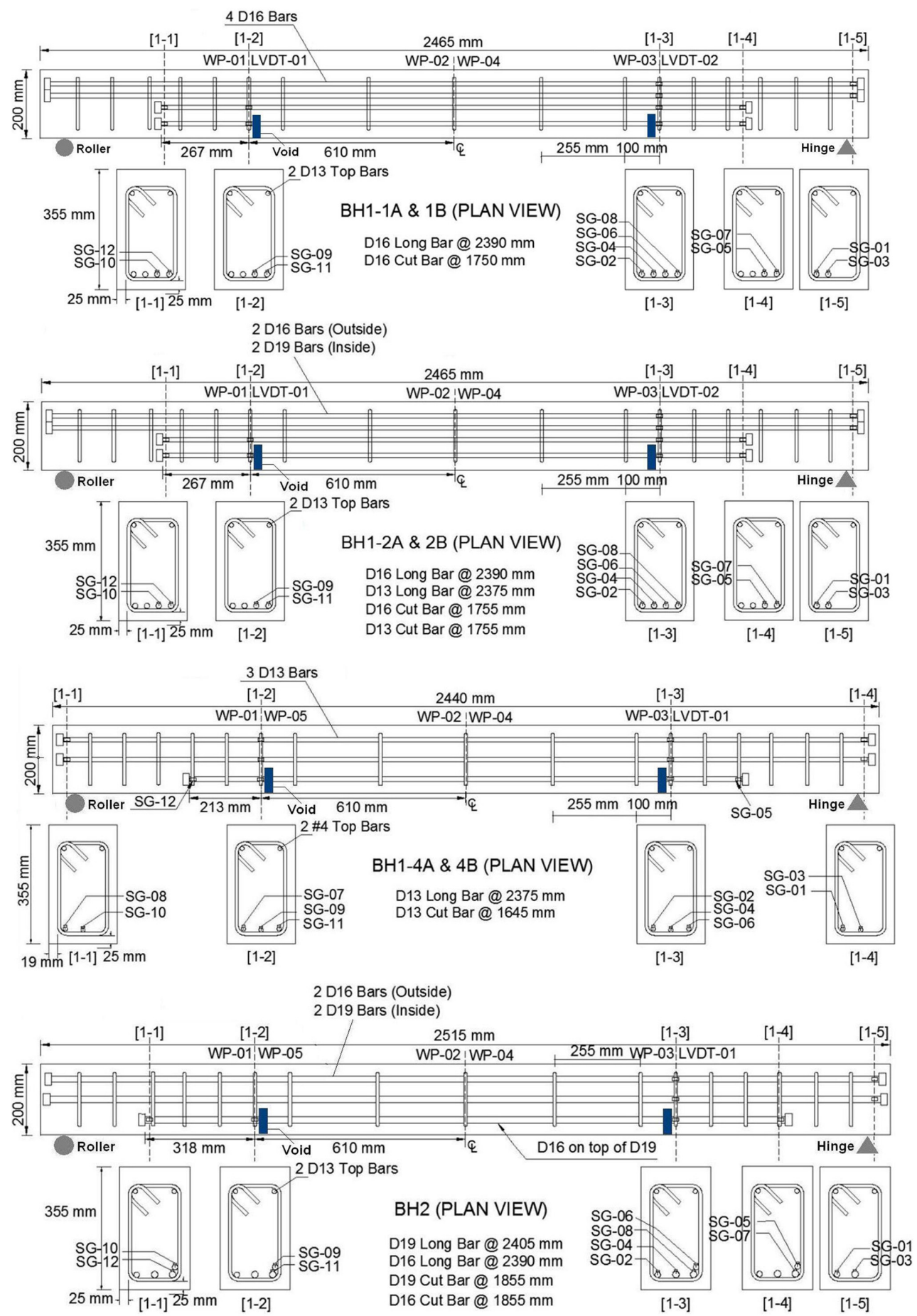

Fig. 3 Test specimens and instrumentation.

iv. Specimens BH1-4A and BH1-4B: Reinforced concrete beams containing three D13 headed bars and clear spacing of $4.25 d_{b}$ between bars at cut-off region, with one D13 bar cut off at $l_{d t}$ of $190 \mathrm{~mm}$ from the loading point.

v. Specimen $\mathrm{BH} 2$ : A reinforced concrete beam containing two D16 and two D19 headed bars and clear spacing of $2.75 d_{b}$ between bars at cut-off region, with one D16 and one D16 bar cut off at $l_{d t}$ of $290 \mathrm{~mm}$ from the loading point. As shown in Fig. 3, two layers of tension reinforcement were placed on one side of this specimen.

For transverse reinforcement, D10 hooked end closed stirrups were used and were evenly spaced at $100 \mathrm{~mm}$ throughout the shear span region and $255 \mathrm{~mm}$ at the constant moment region. Two D13 top bars were used to anchor the stirrups. The beams were painted in a thin white layer and gridded in squares at $90 \mathrm{~mm}$

Table 2 Measured material properties.

\begin{tabular}{c|c|c|c|c}
\hline \multicolumn{2}{c|}{ Concrete } & \multicolumn{3}{c}{ Reinforcing bars } \\
\hline \hline $\begin{array}{c}\text { Compressive } \\
\text { strength, MPa }\end{array}$ & $\begin{array}{c}\text { Modulus of } \\
\text { rupture, MPa }\end{array}$ & $\begin{array}{c}\text { Bar } \\
\text { Size }\end{array}$ & $\begin{array}{c}\text { Yield strength, } \\
\text { MPa }\end{array}$ & $\begin{array}{c}\text { Yield } \\
\text { strain }\end{array}$ \\
\hline \multirow{3}{*}{30.7} & \multirow{3}{*}{5.1} & D13 & 510 & 0.0026 \\
\cline { 3 - 5 } & & D16 & 494 & 0.0025 \\
\cline { 3 - 5 } & & D19 & 479 & 0.0026 \\
\hline
\end{tabular}




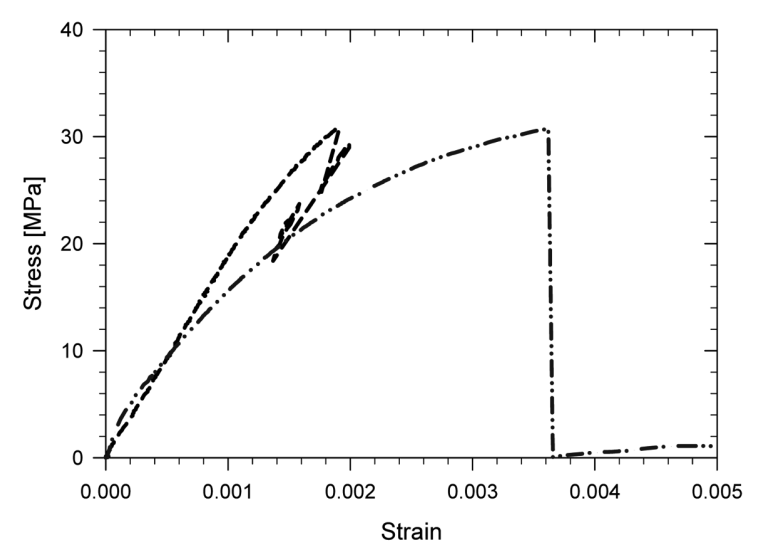

Fig. 4 Compressive stress-strain relationship for concrete cylinders.

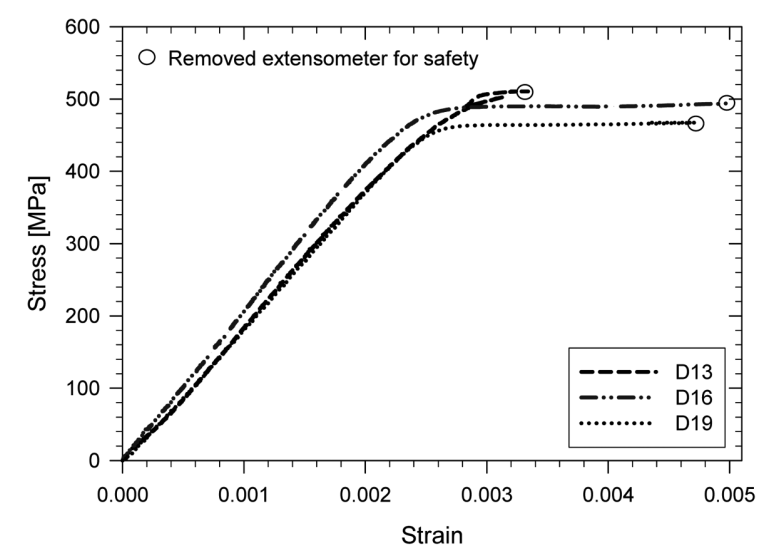

Fig. 5 Tensile stress-strain relationship for longitudinal deformed reinforcing bars

by $90 \mathrm{~mm}$ to allow for more visibility of crack widths and patterns during testing.

\subsection{Material tests}

Table 2 summarizes the measured material properties including the concrete compressive strength and the steel yield strength. Figure 4 shows the representative concrete stress versus strain relationship, while Fig. 5 shows the stress versus strain relationship from tensile tests of D13, D16 and D19 steel reinforcing bars. Note that the displacement control was used, but the strain gauges attached to the concrete cylinders were unable to read the compressive strains after the peak due to the damage (LVDTs were not used). In this paper, the average measured compressive strength of 30.7 MPa from three concrete cylinders was used as a representative value of actual concrete strength for all specimens (Table 2). The average measured steel yield strengths of one D13, two D16 and two D19 bars were 510, 497 and $479 \mathrm{MPa}$, respectively.

\subsection{Fabrication, instrumentation and experimentation}

All nine specimens were fabricated and cast using normalweight concrete $\left(2,400 \mathrm{~kg} / \mathrm{m}^{3}\right)$. Upon measurement, it was discovered that all of the bars were 25 to $75 \mathrm{~mm}$ longer than the specified design length. The length of the cut-off bars were measured and satisfied the provisions for required development length. A total of 12 locations on each setup of the beam were chosen for strain gauge locations. Six strain gauges were attached on the critical section, with four on the cut bars, and the other six were attached at $13 \mathrm{~mm}$ from the head bearing surface (Fig. 3).

The fabrication of reinforcing cages was started immediately after all the headed bars were set. The void spaces on the twopoint load locations were created by using $25 \mathrm{~mm}$ thick pieces of Styrofoam that were cut to fit in the tension reinforcement as well as the placement of the cage into the formwork (see Fig. 3). The void spaces were to ensure that flexural yielding would occur at the desired location (i.e., flexural critical section) upon reaching the ultimate capacity. This testing setup is same as that used by the Bureau of Standards. ${ }^{6}$

A manually controlled hydraulic actuator having a load capacity of $1,335 \mathrm{kN}$ was used to test the nine specimens. The specimens were simply supported and were tested under a two point monotonic loading by a spreader beam. The supports with a diameter of $305 \mathrm{~mm}$ were placed at $90 \mathrm{~mm}$ from the end of the beams. The roller allowed the beam to deflect and rotate on one end. Figures 7 and 8 show the spreader beam connected by four hollow steel tubes to the reaction frame. The spreader beam was then supported by two rollers placed on top of two identical steel bearing plates which were connected to the top surface beam by hydrostone with the intention of inducing point loading. A load cell with a capacity of $445 \mathrm{kN}$ was calibrated and placed on top of the spreader beam and connected to the data acquisition computer. All the setups were carefully placed and adjusted to minimize eccentricities. Beam torsion instruments were designed and made based on the dimension of the beam to prevent the torsion due to the cut bars on one side of the beam.

Four Wire Potentiometers (WP01, WP02, WP03, and WP04) and two $13 \mathrm{~mm}$ Linear Variable Displacement Transducers

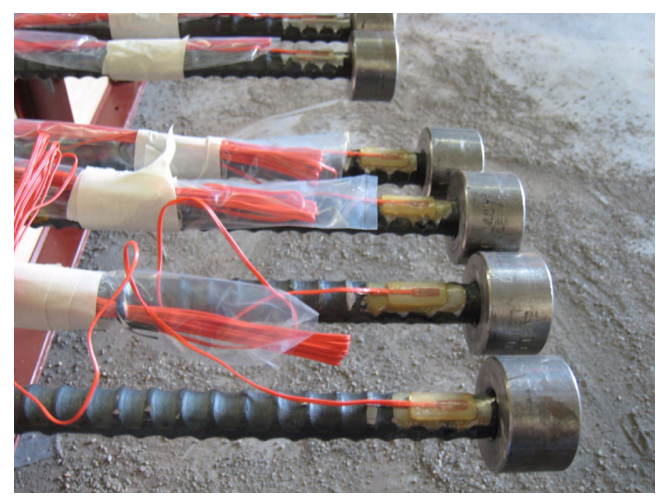

Fig. 6 Strain gauges attached to the headed bar just before the head.

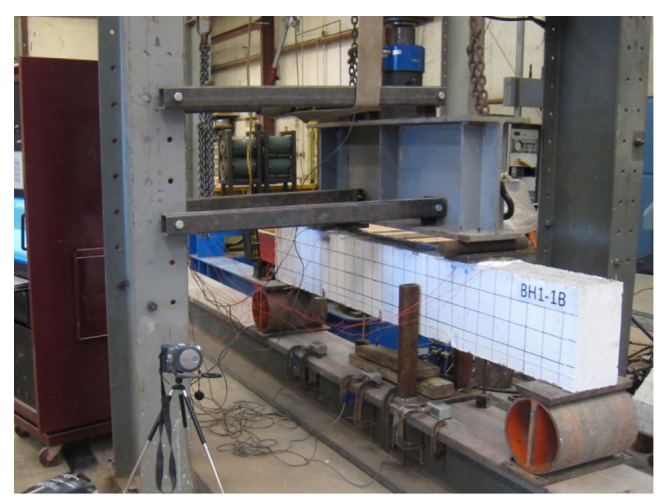

Fig. 7 Test setup overview for $\mathrm{BH} 1-1 \mathrm{~B}$. 


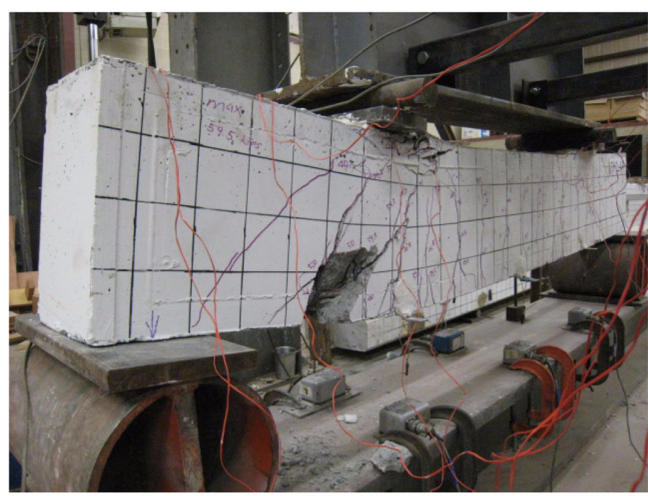

Fig. 8 Test setup and damaged pattern for $\mathrm{BH} 1-4 \mathrm{~A}$.

(LVDT01, LVDT03) were used to measure the deflection of the beams (see Fig. 3). The wire potentiometers of WP02 and WP04 were placed at the midspan of the beams to measure the total midspan deflection. The sensors of WP01, WP03, LVDT01 and LVDT03 were placed beside the void location to measure the critical section displacement. All the vertical displacement instruments and 12 strain gauges on each beam were connected to the data acquisition computer to record the load-displacement relationship as well as the load-strain relationship. After the setup, all the instruments were checked before the actual testing of the beam. The loading rate could not be acquired due to the manually pumped actuator. Therefore, while the testing was in progress, hydraulic pumping was carefully done to make sure the loading steadily increased. The loading stages were chosen to be in $45 \mathrm{kN}$ increments. The LVDTs and strain gauge readings were stored in the data acquisition computer during testing. Loading was stopped at every $45 \mathrm{kN}$ to enable the researchers to mark the crack patterns and photograph the beam. Testing was over when the failure of the beams occurred.

\section{Experimental results}

\subsection{Observed behavior}

Figure 9 show the load-displacement relationship from the responses of displacement gauges for BH1-1B. At the loading stage of $45 \mathrm{kN}$, no cracking had occurred. The first hairline flexural crack appeared at $100 \mathrm{kN}$ at the constant moment region followed by some flexural-shear cracking at the north and south ends

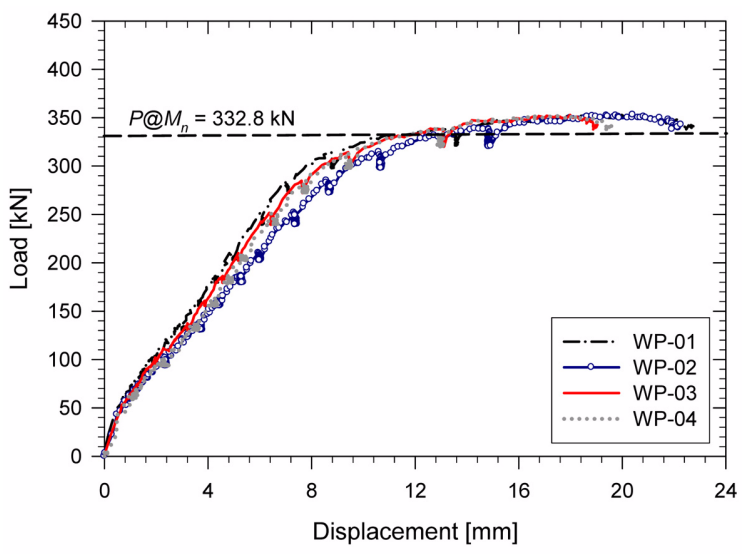

Fig. 9 Load-displacement relationship for BH1-1B. of the beam. Diagonal flexural-shear cracks on both ends continued to propagate when the load reached $135 \mathrm{kN}$. Hairline web shear cracks continued to form as the loading increased every $45 \mathrm{kN}$. These cracks continued to extend further toward the point of loading. Widened flexural-shear cracks on the north end of the beam and extending to the loading point dominated the failure pattern of the beam. Cover spalling and concrete crushing on the top follows when the loading reached at $350 \mathrm{kN}$ (Fig. 8). Testing was stopped at the load of $350 \mathrm{kN}$, and the corresponding average midspan displacement was $21 \mathrm{~mm}$. Similar observations were made for all specimens (e.g., Fig. 10), except for the values of the average midspan displacement and the corresponding load. For example, the average midspan displacements were $33 \mathrm{~mm}$ and $58 \mathrm{~mm}$ for BH1-2B and BH1-4A, respectively, at $270 \mathrm{kN}$ and $265 \mathrm{kN}$.

Figure 12 shows the displacement profile measured for $\mathrm{BH} 1-$ $3 \mathrm{~A}$, respectively. Typically, asymmetric displacement profiles were observed, as either side of the beam failed prior to the other side. Figures 13 and 14 present the responses of the strain gauges attached to the locations indicated in Fig. 4 for BH1-1B and BH1$4 \mathrm{~A}$, respectively. As seen, yielding of steel bars with the ACI 31808 specified development length of $l_{d t}$ occurred. Discussions of the experimental data are provided in the following subsection.

\subsection{Discussion of measured responses}

4.2.1 Flexural yielding, and development and anchorage

The nonlinear behaviors of the beam and reinforcing steel were

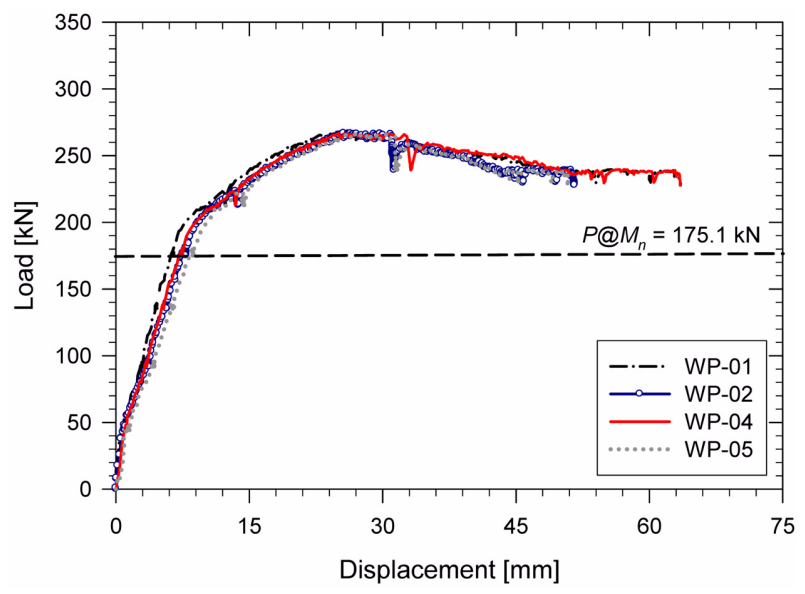

Fig. 10 Load-displacement relationship for $\mathrm{BH} 1-4 \mathrm{~A}$.

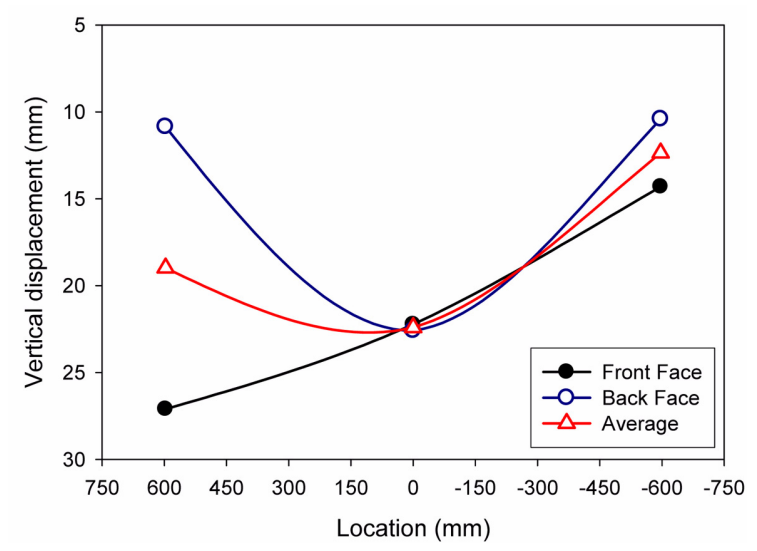

Fig. 11 Displacement profile along the beam length for $\mathrm{BH} 1-3 \mathrm{~A}$. 


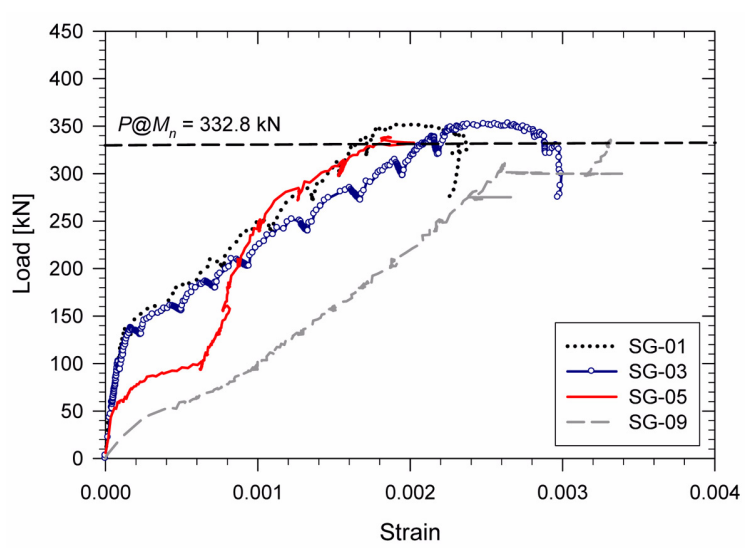

Fig. 12 Load-strain relationship for $\mathrm{BH} 1-1 \mathrm{~B}$.

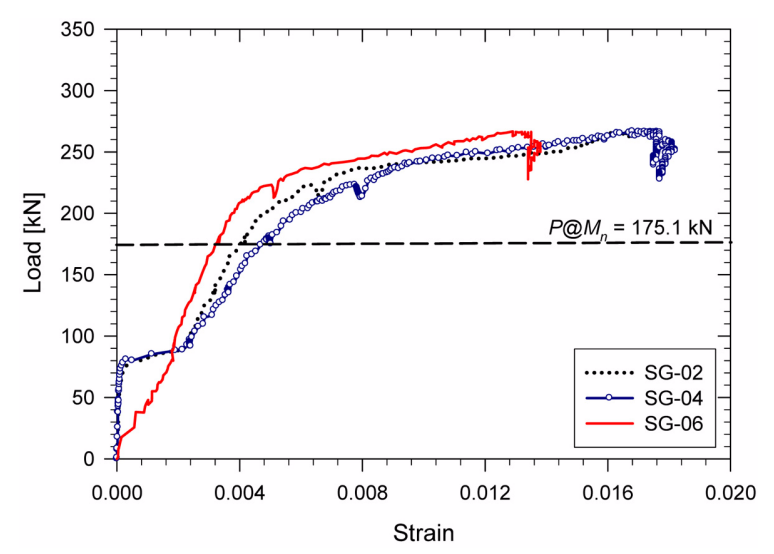

Fig. 13 Load-strain relationship for $\mathrm{BH} 1-4 \mathrm{~A}$.

observed through the load versus displacement relations and load versus strain relations, respectively. The strain gauges located on the loading point/critical section for all specimens did show that the headed bars were capable of developing to full yield strengths as indicated by the large localized strain that occurred before reaching the calculated moment capacity (Figs. 12 and 13). Table 3 indicates a good correlation between the experimentally measured load and the design load with the exception of BH1-3B and BH2 which failed in flexural-shear failure before the moment capacity was reached. Failure of the two specimens to carry the design load can be attributed to the improper casting of concrete which resulted in low uncracked section flexural stiffness and bond deterioration along the reinforcing bar. However, it was observed that all the specimens resulted in a flexural-shear failure at ultimate strength. This is also discussed later in the section regarding the shear span-to-depth ratio. The flexural yielding of the headed bar thus represents that the development length provided for cut-off bars was sufficient to resist the required tensile stresses in concrete.

Additionally, it is noted that no side-face blowout failure was observed for all nine specimens. With a design clear bar cover of about $2 d_{b}$, the test results signal that the anchorage of the head was adequate and validate the ACI 318-08 requirement of minimum clear cover of $2 d_{b}$. The net bearing area ratio of at least $4\left(A_{b r g} / A_{b}\right.$ $=4.5$ to 6.5 in this test) for the head also proved to be effective as indicated by the large strain deformation right before the head of the bar (Fig. 12). Overall, the development and anchorage of the headed bars used for the test specimens were effective for developing their yield strengths.

\subsubsection{Clear headed bar spacing}

The specimens BH1-1B, BH1-2A, BH1-3A and BH1-4A with a design clear spacing of $1.5 d_{b}, 2 d_{b}, 2.25 d_{b}$ and $4.25 d_{b}$, respectively, were used for comparison in this section. For BH1-4A, readings from the strain gauges attached at the end of the long bars and at the critical section of the cut-off bars, respectively, showed that the degree of flexural yielding was small at the end of the long bars and considerably larger as intended at the critical section. However, for BH1-1B, BH1-2A and BH1-3A, strain deformation exceeded the yield strain at the end of the long bars as indicated by SG-01 and SG-03 (e.g., Fig. 12). This might be due to the loss of bond caused by improper casting (BH1-2A) in addition to the severe flexural cracking developed beyond the cut-off section; thus, the long bars had a tendency to slip with respect to concrete. Despite the substantial bond loss, with the head acting as an anchor, the long bars were not able to create a large bar deformation right before the head.

On the other hand, the development of flexural cracking beyond the cut-off section for BH1-4A was not severe enough to cause bond deterioration and large strain deformation for the long bars. This result is also partly due to the wide clear spacing as compared to the specimens with closer clear spacing. The arrangement of the cut-off bars along one side of the beam, rather than in between of the long bars, plus the closely-spaced headed bars and improper casting contributed toward the development of severe flexural cracking on the weakened region (Fig. 8). Initially, the intention of this particular arrangement was to observe the occurrence of sideface blowout failure for the bars being developed within a shorter distance. The outcome of the test might have been different if the cut-off bars were to be placed inside the two long bars. In that case, the long bars would show small strain deformation before the head for BH1-1B, BH1-2A and BH1-3B, as intended, even with closely-spaced headed bars. It was observed that all four specimens including the three specimens with closely-spaced (less than $\sim 2 d_{b}$ ) headed bars and severe bond deterioration (BH1-1B, BH1-2A and BH1-3A) and one poorly cast specimen (BH1-2A), were capable of reaching the design moment capacity with no pullout cone/breakout failure. The pullout cone/breakout failure (see Fig. 1) would show a sudden loss of applied load at near zero level. The load versus displacement for all specimens did not show a sudden loss of applied load to near zero level after the maximum load was reached. This indicates that clear spacing had little-to-no impact on the development of full yield strength of

Table 3 Comparison of measured peak loads and loads corresponding to design nominal moment strengths

\begin{tabular}{c|c|c|c|c|c|c|c|c|c}
\hline Specimen & BH1-1A & BH1-1B & BH1-2A & BH1-2B & BH1-3A & BH1-3B & BH1-4A & BH1-4B & BH2 \\
\hline \hline$P_{\text {exp }}(\mathrm{kN})$ & $220.6^{*}$ & $351.4^{*}$ & 280.2 & 271.3 & 337.6 & 204.6 & 264.7 & 195.7 & 289.1 \\
\hline$P_{\text {design }}(\mathrm{kN})$ & 220.6 & 333.1 & 277.7 & 277.7 & 326 & 326 & 175.2 & 175.2 & 337.7 \\
\hline
\end{tabular}

* Does not have the same a/d ratio (2.6 and 1.7 for BH1-1A and BH1-1B, respectively). 
headed bars for all the specimens. Therefore, the experimental test results of this research can be used to facilitate further investigation of the limit of $4 d_{b}$ on ACI 318-08.

\subsubsection{Effect of failure modes}

Generally, the tension reinforcement of a beam restrained the vertical flexural crack opening. Beyond the cut-off section of the specimens in this experiment, the moment capacity of the cross section was calculated assuming that the two long bars could develop to full yield strength and carry the load. However, the part with no flexural reinforcement developed severe flexural cracks and weakened the region, which is seen in Fig. 8. The shear flow was not able to transmit to the long longitudinal reinforcement. Therefore, the shear flow was transferred by "arch action" rather than a beam action. As such, substantial damages occurred at the back of the head of the cut-off bars, and the long bars did not develop bond stresses along the reinforcement. Although the failure of beams with a short shear span of ( $a / d=1.7$ to 2.6$)$ was characterized by bond failure or split failure along the tension reinforcement, the strain gauges on the two long bars did show large bar deformation just before the head, indicating that the bearing was effective.

The beam displacement profiles (Fig. 11) also indicate that the beam specimens failed in an asymmetrical manner where failure was more severe on one end of the beam. This was also attributed to the unequal amount of steel being placed beyond the cut-off section, which created a very weak region on either side of the beam. In spite of the combination of improper casting, loss of flexural stiffness and one-sided tension reinforcement beyond the cutoff section, the head of the bar still showed an effective measure to avoid anchorage failure and bond slippage beyond the cut-off section, as indicated by the full development of flexural capacity before the complete shear-compression failure. The transverse reinforcement provided throughout the shear span somewhat contributed toward the delay of strength deterioration. The improved confinement of concrete might have avoided the concrete side spalling through the bond with concrete even though the provided clear bar cover was close to a minimum of $2 d_{b}$.

\subsubsection{Summary on closely-spaced headed reinforcement} issue

With the need to address the closely-spaced headed reinforcement issue, this research was conducted to evaluate the current ACI 318-08 provisions regarding clear spacing. In this research, no severe concrete breakout failure, pullout cone failure or sideface blowout failure (see Fig. 1) was observed from the specimens. The closely-spaced headed bars $\left(1.5 d_{b}\right.$ to $\left.2.25 d_{b}\right)$ were deemed to be an effective means in this study and may be acceptable to reduce congestion in beam ends. The beam specimens failed in shear-compression failure after reaching the design moment capacity, while the strain of the headed bar on the critical location did develop to full yield strength (Figs. 12 and 13), even for poorly cast specimens such as BH1-2A and BH1-2B. The relatively poor concrete casting and weakened region at cut-off section should have greatly contributed to the decrease of design moment capacity but this research showed otherwise. The head thickness and head size used in this study appear to be capable of developing upset bearing pressure between the interface of the head and the concrete. Based on the observation, the beam specimens might not have failed in shear compression failure if the two cut-off bars were to be located in between the two long bars. The ACI 318-08 clear bar spacing provision of $4 d_{b}$ is too conservative and not practical, provided that a large amount of steel is needed to fit into a beam, a column or a beam-column joint. The current test data indicate that the beam specimens were capable of developing moment capacity with clear spacing around $2 d_{b}$. However, to make a proposal for the ACI 318 code change, additional research would be needed to evaluate closely-spaced headed reinforcement in unconfined concrete beams or other structural elements.

\section{Conclusions}

In this experiment, headed bars were used in nine beam specimens to investigate their applicability in beam ends where steel congestion is often problematic. The beam specimens were designed in accordance with ACI 318-08 Section 12.6 "Development of Headed and Mechanically Anchored Deformed Bars in Tension." Test data were used to examine the effect of closelyspaced headed bars in simply supported beams under a four-point monotonic loading system. No severe concrete breakout failure, pullout cone failure or side-face blowout failure was observed from the beam specimens. The results and findings from this study indicate that the clear spacing of $2 d_{b}$ may be acceptable for headed longitudinal bars, as opposed to the current minimum limit of $4 d_{b}$. The load versus displacement and load versus strain relationships also support that the specimens were capable of developing to full yield strength and reached the design moment capacity with no brittle failure. However, it is also noted that the findings are only limited to the current experiment and additional research is needed.

\section{Acknowledgements}

The work presented in this paper was supported by U.S DOTRITA grant under No.DTRT06-G-0016/OTCREOS9.1-27 and by the Engineering Research Institute at Seoul National University. The authors acknowledge the assistance of John Paul Badasci and Saagar Patel, who actively participated in the structural testing program as a research assistant at the University of Oklahoma. The opinions, findings and conclusions in this paper are those of the authors and do not necessarily represent those of the sponsors.

\section{References}

1. ACI Committee 318, "Building Code Requirements for Reinforced Concrete (ACI 318-71)," American Concrete Institute, Detroit, MI, 1971, 78 pp.

2. ACI Committee 318, "Building Code Requirements for Structural Concrete (ACI 318-08) and Commentary," American Concrete Institute, Farmington Hills, MI, 2008, 473 pp.

3. ASTM A970/A 970M-04a, "Standard Specification for Headed Steel Bars for Concrete Reinforcement," ASTM International, West Conshohocken, PA, 2004, 8 pp.

4. Joint ACI-ASCE Committee 352, "Recommendations for Design of Beam-Column Connections in Monolithic Reinforced Concrete Structures (ACI 352R-02)," American Concrete Institute, 
Farmington Hills, MI, 2002, 37 pp.

5. DeVries, R. A., Jirsa, J. O. and Bashandy, T., "Effects of Transverse Reinforcement and Bonded Length on the SideBlowout Capacity of Headed Reinforcement," ACI Structural Journal Special Publication, Vol. 180, Oct. 1998, pp. 367 389.

6. Ferguson, P. M., Breen, J. E., and Jirsa, J. O., Reinforced Concrete Fundamentals, $5^{\text {th }}$ Edition, John Wiley \& Sons, Inc., New York, N.Y., 1988, 746 pp.

7. Hong, S.-G., Chun, S.-C., Lee, S.-H., and Oh, B., "Strutand-Tie Model for Development of Headed Bars in Exterior Beam-Column Joint," ACI Structural Journal, Vol. 104, No. 5,
Sept.-Oct. 2007, pp. 590 600.

8. Kang, T. H.-K., Ha, S.-S., and Choi, D.-U., "Bar Pullout Tests and Seismic Tests of Small-Headed Bars in Beam-Column Joints," ACI Structural Journal, Vol. 107, No. 1, Jan.-Feb. 2010, pp. 32 42.

9. Mains, R. M., "Measurement of the Distribution of Tensile and Bond Stresses along Reinforcing Bars," ACI Structural Journal, Vol. 48, No. 11, Nov. 1951, pp. 225 252.

10. Minor, J. and Jirsa, J. O., "Behavior of Bent Bar Anchorages," ACI Structural Journal, Vol. 72, No. 4, April 1975, pp. $141 \sim 149$. 